\title{
In Pursuit of a Youth Life-Purposefulness Program
}

\author{
Mohamed Buheji \\ International Inspiration Economy Project- Bahrain \\ E-mail: buhejim@gmail.com
}

Received: Sep. 3, 2019 Accepted: Oct. 15, 2019 Online published: Oct. 21, 2019

doi:10.5296/ijhrs.v9i4.15680 URL: https://doi.org/10.5296/ijhrs.v9i4.15680

\begin{abstract}
Dwelling on youth Life-Purposefulness, this paper explores how to enhance youth's readiness for future economies. The detailed case study examines how life-purposefulness could be built and facilitated in different youths' status, i.e. graduating youth, graduated, job-seekers, unemployed and youth that are not happy with their achievements, or current status.

The research questions how the technique followed by the 'International Inspiration Economy Project (IIEP) youth summer program' contributes to the capacity of youth participants' life-time inspiration and legacy. The two years' program experience is evaluated in the way they are set-up. The content analysis from literature is reflected in the IIEP program delivery, including the setup of the five phases of the life-purposefulness program conducted. A framework that targets to enhance youth's capacity to leave a differentiated outcome and minimise their zero-status is proposed to cover the literature gap. The researcher argues that the involvement of youth in socio-economic projects during their search for a purpose would create a differentiation in their life-time contribution. The implications for the program and its framework, along with the paper limitations and perspectives for future empirical research, is suggested.
\end{abstract}

Keyword: life-purposefulness, purpose in life, meaning of life, youth economy, youth life purposes

\section{Introduction}

This paper focuses on exploring the means for establishing life-purposefulness through extensive literature review. The literature covers the different definitions of life-purposefulness and how to measure it.

The review shows the psychology of life-purposefulness development and the importance of being curious. Models of life purposefulness and its reactive development social learning are covered. The philosophy of life purposefulness and how to achieve the performance goals go in hand is linked to the ego involvement when we build intrinsic motivation. Buheji (2019a). 
The paper focuses on the importance of developing life-purposefulness framework suitable for youth and manage the areas of fear in the brain. The framework is extracted from the two years' youth summer program carried out by the International Inspiration Economy Project (IIEP) which covered as a case study.

\section{Literature Review}

\subsection{What Life Purposefulness Means?}

A purpose may be challenging to form and may only come from an effortful and gradual development process. Thus, the purpose may come from a deliberate searching and refining process that we term proactive. For this life purpose process to unfold, youth must possess a curious nature for the intentional pursuit of meaningful and rewarding behaviours, Buheji (2019a).

A purpose can be characterised as a life-central aim that shapes a person's identity. However, for this purpose to occur, it needs a framework that provides systematic behaviour patterns in everyday life.

In order to build a purpose that generates continual goals and targets, youth need a framework that provides a resilient spirit towards overcoming obstacles, Buheji (2018c). In this paper, we outline a theoretical model of purpose development besides outlining various essential ingredients to creating a purpose in youth life.

A life-time purpose requires gradual refinement and a maturity that can be differentiated by social learning through observation and then modelling of a community problem. Kashdan and McKnight (2009).

Life purposefulness needs proactive, curious exploration that triggers the interests of youth and makes them more receptive to new experiences and alternative ways to examine themselves and the outside world, (Silvia, 2001). Buheji (2018b) sees that the more youth seek a coherent understanding of their environment, the more they can re-invent their lives. This is supported by Kashdan and Steger (2007) work on life purposefulness. Learning and growing are inevitable by-products of being curious and exploratory (Kashdan, 2009; Silvia, 2006).

Many researchers now see that life-purposefulness is beyond momentary curiosity, as it transforms a goal into a long-lasting interest, called a purpose. Buheji (2019a), Kashdan and McKnight (2013), Sheldon and Kasser (1998). If a purpose is provided by a framework driven program that builds behaviour patterns, then different resources as time and energy, need to be effectively managed. Bandura (1977).

\subsection{What Differentiate a Youth Purpose?}

Despite the fact that the presence of purpose can mean the availability of passionate interest, not all interests or passions can be construed as a purpose. A purpose can motivate a person to dedicate resources in particular directions and toward particular goals. Therefore, engagement with community problems helps youth to learn how to be devoted to their target. Setting such 
youth engagement with socio-economic issues, as part of purpose building and alignment program, allows these youths to be more resilient to obstacles and capable of managing strains. Buheji (2018c).

Persistence is more comfortable with a life aim that resonates across time and context. It is easier to confront long-lasting, difficult challenges with the knowledge that there is a broader mission in the background. Moving in the direction of a life aim can facilitate other elements of well-being, such as life satisfaction, serenity, and mindfulness (Wilson \& Murrell, 2004; Wong \& Fry, 1998). Equally impressive is the idea that a behavioural commitment to purpose in life might compensate for reductions in other elements of well-being during periods of difficulty and adversity. Dacey (1989), Bandura (1977).

Picasso (1881-1973) used to say The meaning of life is to find your gift. The purpose of life is to give it away. This paper investigates what makes certain youth are more capable of creating lives that are most worth living, while others do not. It is about understanding how youth could stay on the course toward fulfilling a life goal despite obstacles, failures, and the absence of positive feedback - having a purpose in life that offers unique and healthy psychological insight that stays focused and successful in the long-term.

\subsection{Setting and Gauging Youth Life Purposefulness}

Most of the existing work on purpose in life has relied on global self-report questionnaires. This type of work is not suitable, particularly today, for youth from 13 to 29 years old. Setting youth for life-purposefulness means setting a life that has a purpose or mission with goals that are pursued because they are intrinsically enjoyable or essential and need to be continuously assessed. Steger and Frazier (2005), Sheldon and Kasser (1998).

Once youth are equipped with their purpose, then they would be ready to clarify and elaborate on how their goals are woven into their core values, which help to build their meaning of life. This builds youth with an overarching value. However, there is a gap in gauging and measuring life-purposefulness, which correlates the consequences of purpose. Our definition of purpose provides an entry point to begin creating assessment devices to study purpose in life more directly. Additional details of our conceptual model of purpose are outlined elsewhere (McKnight and Kashdan, 2009). The available measurement tools proposed for aligning the life-purposefulness can help to be used as constructs for a program that build or rehabilitate the meaning of life and setting the purpose of life for youth. Silvia (2001), Steger and Frazier (2005); Wong and Fry (1998).

\subsection{The Psychological Development of Life-Purposefulness}

A life purpose needs to be fostered through constructs of motivation, self-determination and life meaning approaches that identify the challenges that come from the biological vulnerabilities, psychological processes, and social environments that face any purpose in life attempts. Buheji (2019b).

People with a stronger Behavioural Approach System (BAS) and weaker Behavioural Inhibition System (BIS) possess a pattern of thoughts, feelings, behaviours, and motivational tendencies that provide an advantage to finding and living in a way that is consistent with a 
purpose. BAS found to be responsible for sensitivity to potential rewards and ways of attaining them. While BIS found to be responsible for sensitivity to a potential threat, punishments and initiatives that lead to resistance to change or avoidance of danger; people with stronger BAS are found to have better capitalization on their internal experiences.

Another ingredient to the development of purpose is the pursuit of self-concordant goals. Through innermost values and interests, we can define the feature of self-concordant goals (Sheldon and Kasser, 1998). Self-concordant goals help to build self-determination and are associated with more significant effort and attainment. Factors that increase the likelihood of self-concordant goals and their successful pursuit are relevant to purpose development.

Development of purpose is best when we better understand and strengthen our innermost values and interests. Each of these ingredients can lead to the development of purpose, which, when present, offers insight into the totality of a person across time and context. These ingredients are not sufficient for understanding the genesis of purpose, besides developing interests and passion. It is important to note that these ideas merely form a set of testable hypotheses and a way of developing purpose.

Generally, so far, literature mentions three ways for the development of purpose. The first approach focus on being proactive in involving effort over time and only resulting in a purpose after gradual refinement and clarification. The second approach is focused on being reactive to transformative life events where the possibility of life purposes arises. The third approach comes through social learning. Through social learning, we form the purpose through observation and modelling. We provide greater detail for these processes below.

A purpose may be difficult to form and may only come from an effortful and gradual development approach. Thus, the purpose may come from proactive refinement. For this approach to unfold, we expect that a person must possess a curious nature for the intentional pursuit of meaningful and rewarding behaviours. The proactive development approach helps to form interests that lead to curiosity as per Silvia (2001). As an entry point, people need to be aware, open, and receptive to new experiences and alternative ways to examine themselves and the outside world (Bishop et al., 2004; McCrae, 1993).

The more a person seeks out novel and potentially rewarding behaviours, the higher the likelihood that the person will form a coherent understanding and develop his/her their meaning of life (Kashdan and Steger, 2007). In order to develop a purpose from pursuing and engaging new and challenging events, youth are expected to recognise and capitalise on situations that allow for the synthesis of potentially illuminating experiences. The literature needs more programs that help to test how youth can find what supplies their stamina, focus and capacity to adapt to the demands of everyday life effectively. Amabile (1982), Bandura (1977).

\subsection{Life Purpose and the Importance of Being Curious}

Studies show that learning and growing of any life purpose are exploited by curiosity and exploratory activities (Kashdan, 2009; Silvia, 2006). Living with curiosity is expected to be integral to the process of developing a purpose. Curiosity attracts people to new experiences. 
Self-expansion is inevitable, no matter how slight, when a person is exploring the unknown or challenging the limits of their knowledge and skills. When people feel curious, there is an intense desire to explore or take advantage of opportunities to expand the self, Kashdan (2009). This expansion process can include clarifying and strengthening pre-existing interests and values (depth), or the construction and broadening of interest and value categories (breadth), Buheji (2019b).

The expansion caused by curiosity can lead to interests or passions, defined as reliable intentionally sought after sources of joy and meaning (Buheji, 2019a; Silvia, 2001; Vallerand et al., 2003). These sources of enjoyment and meaning are important. However, interests and passions vary in the degree to which they are connected to other elements in a person's life narrative, personality, or identity. Passions found to exploit the core of a person's identity.

Many instances of curiosity are transitory experiences that might capture attention and be satisfying but fail to hold attention and transfer into a stable, lasting structural element of the self (Loewenstein, 1994). Other ingredients are needed to explain how momentary curiosity can transform into long-lasting interests and in some cases, the formation of a purpose. Buheji (2019a).

Effort and ability, however, are not the only requirements for proactive purpose development. As a person curiously seeks out environmental data, they will encounter random stimuli that may provoke a response. If those random stimuli provide the opportunity for a strong positive response, then the direction of curiosity may now be dictated for the foreseeable future.

Developing a purpose begins by observing how the behaviours result in specific outcomes and associating those behaviours with the recognised outcomes. As the outcomes become more pleasing, the observer tries to mimic them to reach the same ends. Even sometimes, we take note of the social divergence that is caused by these behaviours.

When we observe others behaving in ways that elicit positive emotions, this psychological curiosity would likely affect our future behaviour. Studies show now that the purpose of life does not come only from a laborious act of self-discovery, or the chance of occurrence of a transformative life event, but even from the mere curios observation of another's behaviours and the associated emotional reaction that was paired with those behaviours.

\subsection{Models of Youth Life Purposefulness}

Life-purposefulness models may appear similar, but in reality, they differ on the outcomes and their level of dependence on the external or internal resolution. The development of any life-purposefulness model is expected from trial and error, to explore the alternatives and choices that help to build the realisation of the satisfactory solution. Studies show that in order to build a youth focus life purposefulness model, we need to have a proactive and curios program that helps them to overcome all the psychological barriers and exploit their internal assets.

Literature still has a gap in relevant setting programs that can be like a compass for their life and enhance their social interactions and stimulates the efficacy of their decisions. Such 
models would help dictate their curiosity and develop their capacity to link things together.

The models help transform a person's focus and sense of personal meaning and provide alternative pathways for life development. Having life purposefulness models would help us to reduce our waiting for causalities of life transformation that might happen due to sudden shocks as heart attacks, illness and death of children, and severe and terminal illness diagnosis. i.e. with model availability, we become more reactive to all the challenges that would be obstacles in life-purposefulness.

Bandura (1977) sees that the 'social learning' model help people to observe others. When youth observe their parents, siblings, friends, and neighbours behaving by religious faith, those behaviours become "normalised" and soon become part of their purpose. The more a community fosters these behaviours, the stronger the religious following becomes.

\subsection{Philosophy of Life Purposefulness as Performance Achievement}

Studying philosophical issues such as purpose in life stimulate the researchers to move beyond variable-centric approaches to address person-centric approaches. For example, we could expect that people develop a purpose through all or a combination of the three developmental pathways. A person may be actively seeking and developing a purpose that was once learned from another person's behaviours.

Self-determination theory (SDT) help to build the motivation of needs for competence, psychological growth, integrity, and well-being. SDT help to distinguish goals or outcomes or suggesting the different types of goals that have different behavioural and affective consequences. SDT is necessary for purpose-driven motivation, as it gives autonomy based on intrinsic motivation and makes youth freely engaging in socio-economic or community activities that they find interesting, which provide novelty outcome and optimal challenge. Buheji (2019b).

Deci and Ryan (2000) seen that life purposes are like human trajectories that lead to differentiated development and competencies. Such purposes give youth greater autonomy, which leads them to be integrated within the social community.

Dweck (1999) outlined theories that differentiated purpose achievement in terms of both demonstrating and developing competence where such terms are seen as forms of ego involvement by performance and learning goals. Such exercise would help to build self-evaluative focus in which individuals seek to demonstrate high ability, whereas task involvement pertains to people being less concerned with self-evaluation and they are standing relative to others. Thus, ego involvement or performance goals involve attempts to gain positive or avoid negative judgments about one's abilities and expanding one's competencies. When people hold performance goals, they would have the self-esteem to demonstrate to others that they are competent. Such self-esteem tends to create youth with no blame to others but themselves.

When people seek challenges with a purpose, they gain self-esteem from being fully engaged in an activity or using their skill to achieve something valued and tend to focus on how to 


\section{Ml Macrothink}

improve in the face of possible failure, depending on intrinsic motivation. Dweck (1999) seen that such intrinsic motivation, when applied to a certain achievement domain, can be experimentally induced with specific programs. The literature on goals pursuits searches for a broader examination program that correlates with goal-directed behaviours. In his Flow Theory, Cziksentmihalyi (1990), called for purposeful experiences of total absorption in activities of non-self-conscious. Cziksentmihalyi believes that when people experience flow, the purpose of the activity is the activity itself, and this would create a prototype of intrinsic motivation.

According to Cziksentmihalyi, people will experience flow when the demands of the activity are in balance with individuals' capacities. Thus, like Deci and Ryan (2000), Cziksentmihalyi suggested that intrinsically motivated behaviour requires optimal challenges.

\subsection{Establishing Life-Purposefulness by Overcoming Areas of Fear in the Brain}

One of the main challenging obstacles towards establishing life-purposefulness is managing the areas of fear. This management of fear starts with overcoming the reaction that is triggered after the association of the opportunities and the choices with sensory cortex first. The fear of the life-purposefulness then needs to be managed more in the Thalamus, the Hypothalamus, the Amygdala and the Hippocampus in consequence.

In order to create a life-purposefulness journey from the area of rest where we feel safe, we need first to reach the evolution area where (goals and life effect would be set towards overcoming difficulties. Once we start dealing with the challenges and problems with confidence, we would enhance our experience through specific learning areas. This would be achieved only if we pass the area of fear which creates the mistrust, excuses and youth vulnerability. The whole process is illustrated in Figure (1).

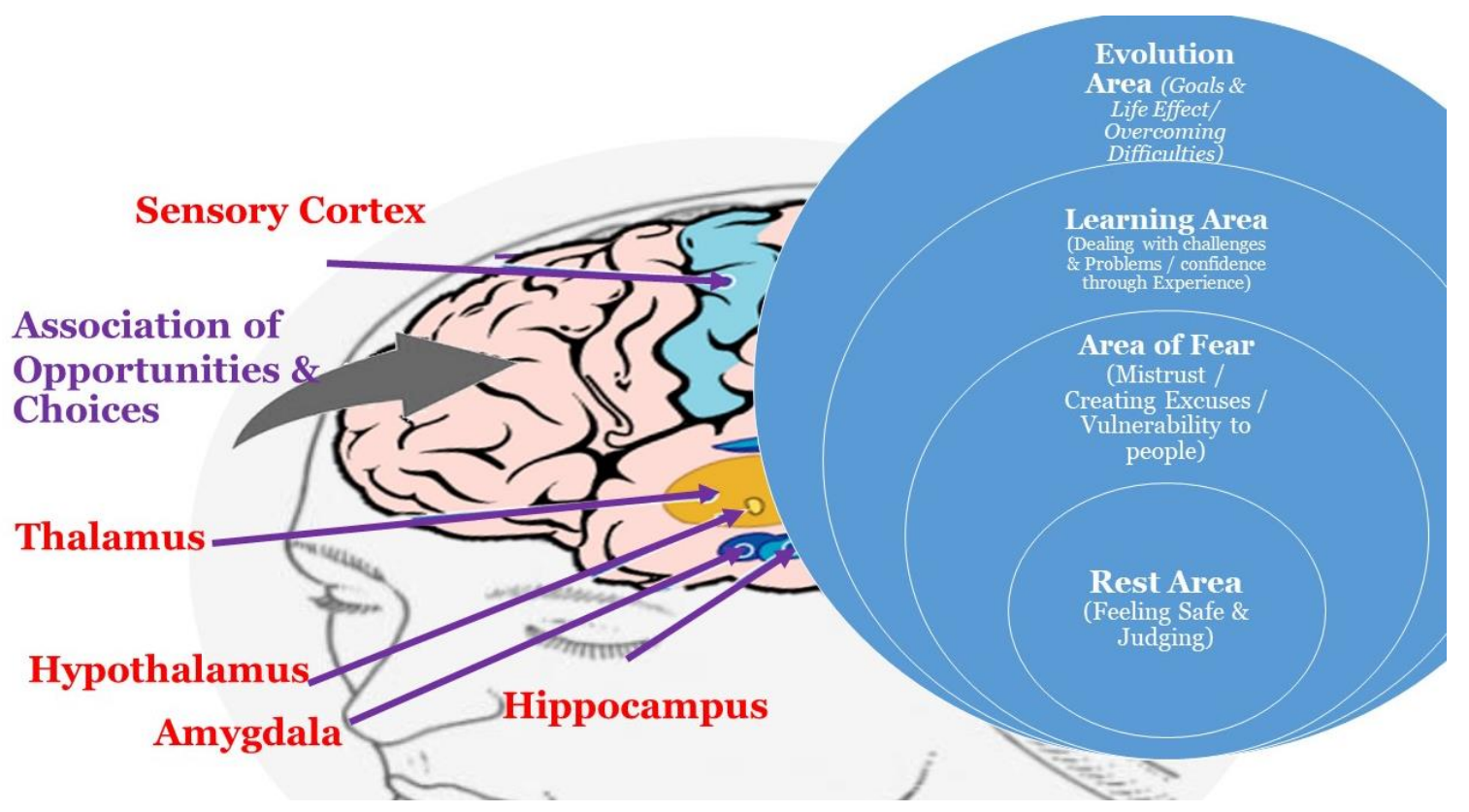

Figure 1. Areas of Fear in Brain once faced with Life-Purposefulness Goal 


\subsection{The Importance of Life-purposefulness Framework}

Synthesis of all the previous sub-sections in this literature review shows it is about time to address the gap of the life-purposefulness framework, specifically for youth. Set a youth life-purposefulness framework means they need to be ready for future economies based on thinking of new ways to both managing resources, adapting to sophisticated future expectations. Their resilience will strengthen developed countries to the challenges of re-exploring available human resources potential wealth. Buheji (2018a).

Any life purpose framework should target to focus on the exploitation of the undiscovered pre-emptive of human assets. The link between the realised human assets raise the returns and distinguish the competitiveness of countries and societies.

The framework focus on raising makes the individual self-discover the purpose paths, the options that could come from it till decisions are made.

When young people know their goal, the exploration of their purpose paths raises their "passion". This has been evidenced for all generations, but fast and complex for this generation, especially in the light of technological and very fast global developments.

The framework should address the purposeful thinking of the "new paths" which could come from the exploration of field research. The exercises also emphasis the purpose of discovery and its sustenance techniques. The framework implementation targets the youth faith as the faith is built around believing in something unknown.

The researcher has proposed to link the youth purposes with their life choices to extract their options and opportunities in different stages. This means the participants could determine the project opportunities based on factors of change through the past and the future. Thus, the framework would be more effective if could include the phenomena and the trends that influenced the participant life or his community and what may affect them in the future. Understanding the influence of the future and realising the effect of the past could help the youth to be more selective in their decision-making. Bandura (1977).

\section{Methodology}

Based on the extensive review and synthesis of the latest literature on life-purposefulness, the researcher questions how the different dimensions of life purposefulness facilitate and enhance youth capacity to leave a differentiated outcome and minimise their zero-status. The empirical part of this study draws on a qualitative case-study methodology (Eisenhardt and Graebner, 2007). Since the paper is exploratory, as per Eisenhardt and Graebner (2007) interpretive methodology, the research mixes the theory and the data in order to interact and to influence the methodological choices.

The detailed case study examines how life-purposefulness could be built and facilitated in different youths' status, i.e. graduating youth, graduated, job seekers, unemployed youth and youth that are not happy with their achievements or current status. The research questions how the technique set in the program followed by the International Project of Inspiration Economy (IIEP) contributes to the youth participants' life-time contribution. 
The two years' program experience is evaluated in the way they are set-up. The content analysis was performed from literature and the monitoring of the on-site program delivery. Structural analysis of the life-purposefulness program is conducted, based upon researchers' observations and literature reviews will be made. (Shah 1998).

\section{Case Study}

\subsection{Introduction to IIEP Youth Life-Purposefulness Program}

"Our Life-Purpose - Our Choices - Our Decisions", is a piloted program that consists of workshops then followed by project phases and a competition that was carried out repeatedly in consequence of two years in the summer of 2018 and 2019, as part of International Inspiration Economy Project and in collaboration with the Inspiration Economy Society in the Kingdom of Bahrain. The program addresses the rising statistics of the NEET (Not employed, not in education, not in training) youth of the ages of 15 till 25 years which as the official statistics of the Bahrain Ministry of Labour reached 10,400 youth, mostly university graduates and they represent $12 \%$ of the total unemployed in the country. The statistics coincide with the statistics, which estimates that it is about $20 \%$ of Arab Gulf Countries graduates, the majority are females, wait to receive a job only after two years. Today it is estimated that more than $30-40 \%$ of graduate students in the rest of the Arab countries are waiting and do not get a job for more than two years. Driouchi and Harkat (2017).

The program targets to identify clear life-purposes paths, choices and decisions for graduating students, youth graduates, job seekers, the unemployed and youth that are not happy with their achievements or current status. This program also comes in a particular time where 1 out of every two graduates do not believe that their studies have qualified them for the job.

The series of life-purposefulness workshop targets to create a change in the mindset of participating youth about seeing and experiencing life as a series of small stories created by small projects. The projects followed practical steps that need to be taken to face the challenges of any project or circumstances that might face any human during his/her life journey.

The Life-Purposefulness program was designed into five phases:

Phase I-Pre-Trial Workshop: In this phase, the target was to inspire the participating youth to discover their life purpose and see it as tracks that are going to develop options and would develop its clarity and resolution with the frequency of attempts. These attempts would improve our choices and decisions. This phase is expected to take five days.

Phase II- Development of a Proposed Project Model: This phase, the participants are expected to go through initial field application, study problems, opportunities, and develop a work plan. This phase, each team are expected to come up with individual and team project within sixteen days. Dacey (1989).

Phase III-Models Review: In this phase, a peers'-review workshop, simulate the importance of life pauses. The five days' workshop is also carried out to help youth appreciate the 
importance of observing, absorbing and realising lifetime opportunities, whether hidden or visible; besides learning to exploit opportunities from problems. Then how to set a revised life-purposefulness plan based on the simulated project pauses.

Phase IV-Completion of field implementation and fulfilment of the phase III action plans. In this phase, the youth participants would learn to avoid procrastination and improve their visualisation of the life-purposefulness targeted outcome, in similar analogy to the project targeted outcome.

Phase V-Projects Competition. The target of this phase is to simulate that lifetime is like a journey where we have to deliver results and outcomes before we expire or leave the train of life. Learning to create a judgement on the projects of the different team also would help the participant to learn to do effective and unbiased self-assessment based on life-purpose focus, utilisation of choices facts and unique achievements based on the selective decision making.

\subsection{Definitions of Life-Purposefulness Program Keys}

Life-purpose Tracks: impact, target values, community level, country, family and circumstances, determined by specialization, desire or new experiences. Options: opportunities, probabilities, future perceptions (quest for employment, quest for exploration, desire for stability, transition, desire for new experience). Decisions: Recognition and acceptance of the current situation, defining the transformation requirement, managing transformation, change and development, building the new will and will, developing new upward plans, taking and eliminating options and perhaps specific paths.

\subsection{Type of Projects of Life-Purposefulness Program}

In order to simulate a life-purposefulness journey, the IIEP try to inspire the participants to focus on socio-economic and community projects. Such projects found to help re-invent the life of the contributing participant and improve their capacity in social leadership, as per Buheji (2018b). Socio-economic projects as poverty elimination, youth type of addiction, youth migration, improvement of educational outcomes, family stability, improving productive families' outcomes, women and youth empowerment; are thought to create paths of mindset that exploit the intrinsic powers and guide the participants to attain life-purposefulness with minimal extrinsic resources compared to the outcomes expected.

The participants are asked to choose a project that relates to their life-purpose or the choices they want to explore to raise the return on the efforts invested by the beneficiaries. The participating youth are given a simple life-purposefulness formula, i.e. capacity vs demand, where capacity could be raised by focusing on either availability, efficiency and effectiveness.

In order to learn to manage their life-purposefulness yield, the participants would be evaluated and judged on their capacity to develop the 'social production yield'. Besides, the 'Availability x Quality x Efficiency' formula, this yield also would come from the project 'elimination of waste' and 'improvement of the value-added outcome'. It is a resemblance of the life journey projects expected. 


\subsection{Goal of the Competition}

The Life-purposefulness competition targets to identify the clear paths, choices, options and decisions for graduating students, graduates and job seekers to help them build clear goals for their career and life purpose, followed by practical steps, regardless of the challenges and circumstances facing them.

The expected outcomes of the life-purposefulness program are to create a clear vision for these youth graduating students, graduates and job seekers and modelling alternative options for similar groups of youth. The competition targets to establish a proactive clear vision of future career for the youth students, graduating or graduated job seeker.

The competition is supposed to help the participants to rearrange their priorities at each stage during the project implementation on a sound scientific basis through modelling alternatives and work options.

Through experimentation, the project would help to build more explicit life journey decisions that are simulated to overcome the obstacles and take advantage of opportunities. The projects competition help youth to design an effective decision-making process and ensure it address their life-purposefulness.

The output of the life-purposefulness competition program targets to create a graduate or a young man that discover his primary purpose of life, choices and can making effective decisions without procrastination, or a graduate who discovered his/her tracks, but did not benefit from them in increasing the alternatives, or the choices before making the decisions. This competition should help youth to create simple, continuous steps that lead to significant leaps. Figure (2) represents the differentiation between youth with life-purposefulness and those without.

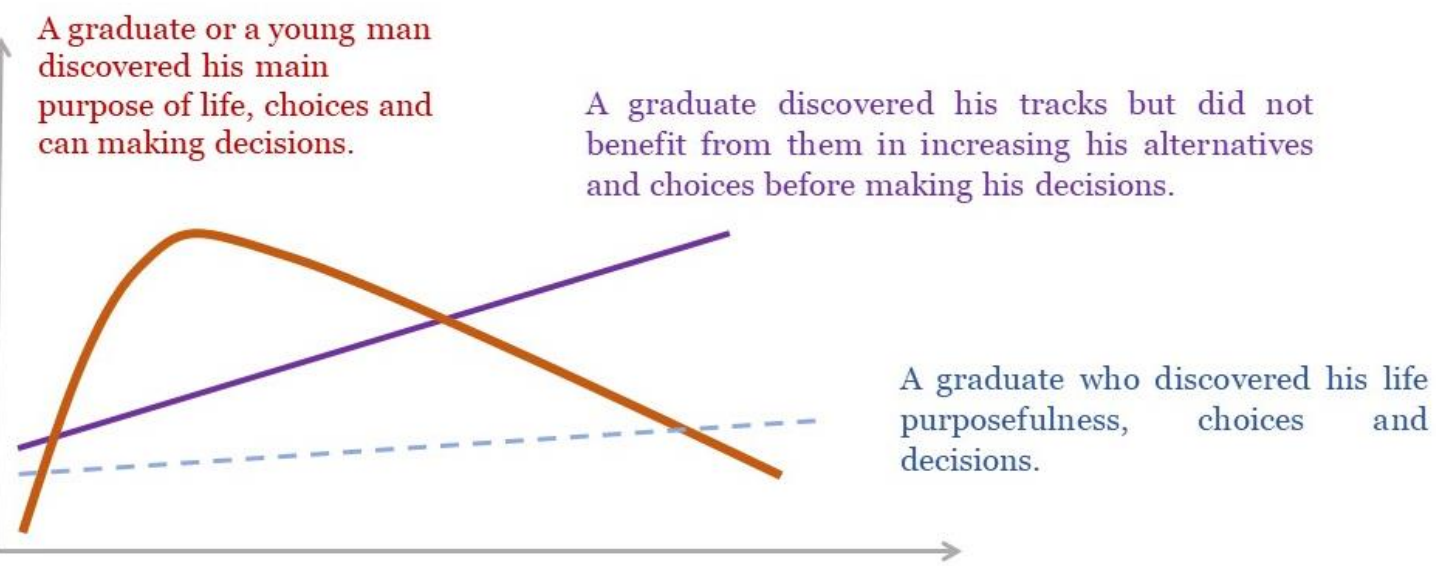

Figure 2. Illustrate the Differentiation of Youth with Life-Purposefulness

Therefore, the program targets through this competition youth graduates in a speciality but with no work, or a graduate in a speciality but do not know what to do or graduate looking for any work, or a young man began to learn about laziness, or a young person consistently 
knocking the door of employment centres or someone who fear that he/she would be eliminated because of tight budgets, or a young individual who has left the job looking for another job. Besides these types, the program is also suitable for youth who are fed up with waiting, or frustrated by the opportunities available, or those aiming to capture a leading opportunity.

\subsection{Design of the Life-Purposefulness Exercises in the Program Workshops}

\subsubsection{Introduction to Exercises Designs}

The exercises were designed to improve the level of readiness of the youth graduates, or the job seekers entering the labour market. The exercises help the participating youths to set life-time targets, be available in the volatile, unstable and renewable labour market. Since the gap towards a differentiated achievement widens every day, where today's youth do not make a decision related to their life purpose; the exercises in the program focused on making a focus on demand through getting involved in socio-economic, or community problem-solving.

\subsubsection{Life-Purposefulness Tracks Exercise}

\subsubsection{Identifying Life-Purposefulness Tracks Exercise}

The exercise helps to define the tracks of youth's values, feelings, ideas, roles, capacities and abilities, and how to exploit them to optimise their achievements of goals and responsibilities in relevance to their mission in life. This exercise helps to point out how to control the paths by understanding internal and external values.

The exercise focus on identifying the internal capacities that help to identify potential tracks in the available youth assets and internal wealth.

Based on the points (tracks of life-purposes) identified in the tables, the youth are encouraged to explore their feelings and see how they could evolve gradually to things they are passionate about. This passion is measured by what these youths see themselves persist and persevere about.

\subsubsection{Discovering Unique Tracks in Life-Purposefulness Exercise}

The "Unique Tracks" exercise is designed to identify the points that youth could distinguish themselves with during their lifetime journey. The exercise focus on exploiting the unique paths that would differentiate their livelihood, based on their talents, abilities and passion. Such paths need to be polished by the youth experience, learning and discovery.

Since alongside all purposeful paths one could also have resources, abilities and emotions, the youth choices and decisions are challenged here based on the four squares the talents, the resources, the capacities, the passion.

An inventory of all internal and external resources, abilities, feelings are taken to discover their maximum joy and fulfilment.

\subsubsection{Determining the Directions Life-Purposefulness Tracks Exercise}

The goal of the exercise to determine the area of the life purpose tracks according to the main interests of the contest youth participant. It also contributes to determining the accuracy of 
expectations and reduces mistiness.

The participating youth are asked to evaluate their basic values taking into account the remaining dimensions.

\subsubsection{Choices Exercises}

\subsubsection{Determining Future Choices Based on Trends}

The exercise aims to determine the choices based on factors of rapid changes in time, i.e. the past, the present and the future. According to the trends, the participating youth is expected to identify the best options after connecting them and realising how they contribute to better decision-making.

The participants are required to determine the type of factors influencing their choices according to specified weights. The factors affecting such weightage options is whether they help these youths to be proactive, or be available to the challenges.

The exercise helps the participating youth in building applied knowledge through realising their social, financial, natural and human capital assets.

\subsubsection{Innovating with New Choices of life Journey}

The goal of this exercise is designed to create innovative interstitial options and hidden opportunities at all stages of the next life.

\subsubsection{Decision-Making Exercises}

\subsubsection{Understanding type of Steps of Life-Purposefulness Decisions}

The exercise is designed to support initial decision making that will help the youth to see what they want to achieve in life, in the short and long term. The slogan of the stage and this exercise is "Never sit at home or start your work from home". The challenges of making the right decisions begin with the knowledge of their paths and alternatives.

\subsubsection{Zero Waiting Exercise}

The exercise aims to support the methodology (zero waiting). The idea is to make the participating youth appreciate that the spirit of the specifying the new paths

to make the most accurate decisions the future and life thus to raise the capacity for decision-making that makes a significant evolution to the quality of life.

\section{Discussion and Conclusion}

\subsection{Reflection on the Theme of the Life-Purposefulness Program}

Having a youth or a community with clear life-purposefulness create a competitive edge and a differentiation for any country. Therefore, this paper provides explanations for building youth life-purposefulness levers through a program that create competition through socio-economic projects that simulate the life journey at different four stages. The program integrated the concepts of life-purposefulness extracted from three distinct kinds of literature. 
The four stages target to identify the opportunity recognition, improve the lifetime project design and implementation helped to identify the type of life challenges that need to be faced in order to leave a legacy. Therefore, the program framework was structured to create artificial or sudden brain stimulations such as sensory sources as (visualising, hearing, touching, etc.). Such stimulation creates waves of thinking to identify paths of life (towards mental processes) that lead to better outputs that prove the utilisation of best options and decisions, such shown in Figure (3).

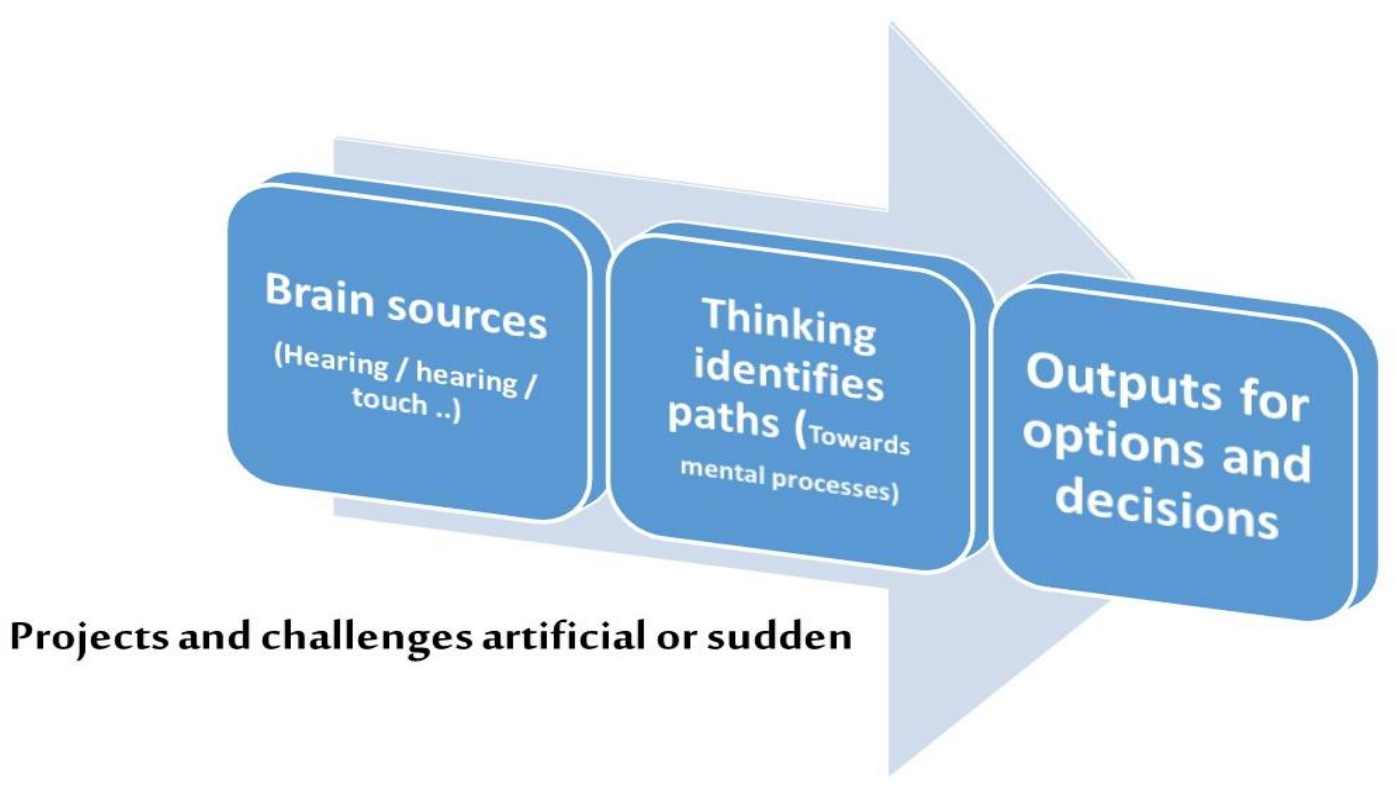

Figure 3. Illustrate the Reflections targeted from Life-Purposefulness Program

\subsection{The Framework of Designing a Youth Life-Purposefulness Program}

To help youth verify their values, the program helps to select five behaviours that would lead them to determine the points controlling their life paths, and then improve what would distinguish them from others. The framework proposed help to build the focus of life goals and take selective efforts according to the tracks specified, starting with humbleness.

The framework focus on the achievements required based on the best options and ensure that determination towards objective is part of the decision making. The focus as per the framework can be increased through taking pauses that increase the flow of the inspiration, as per Figure (4). 


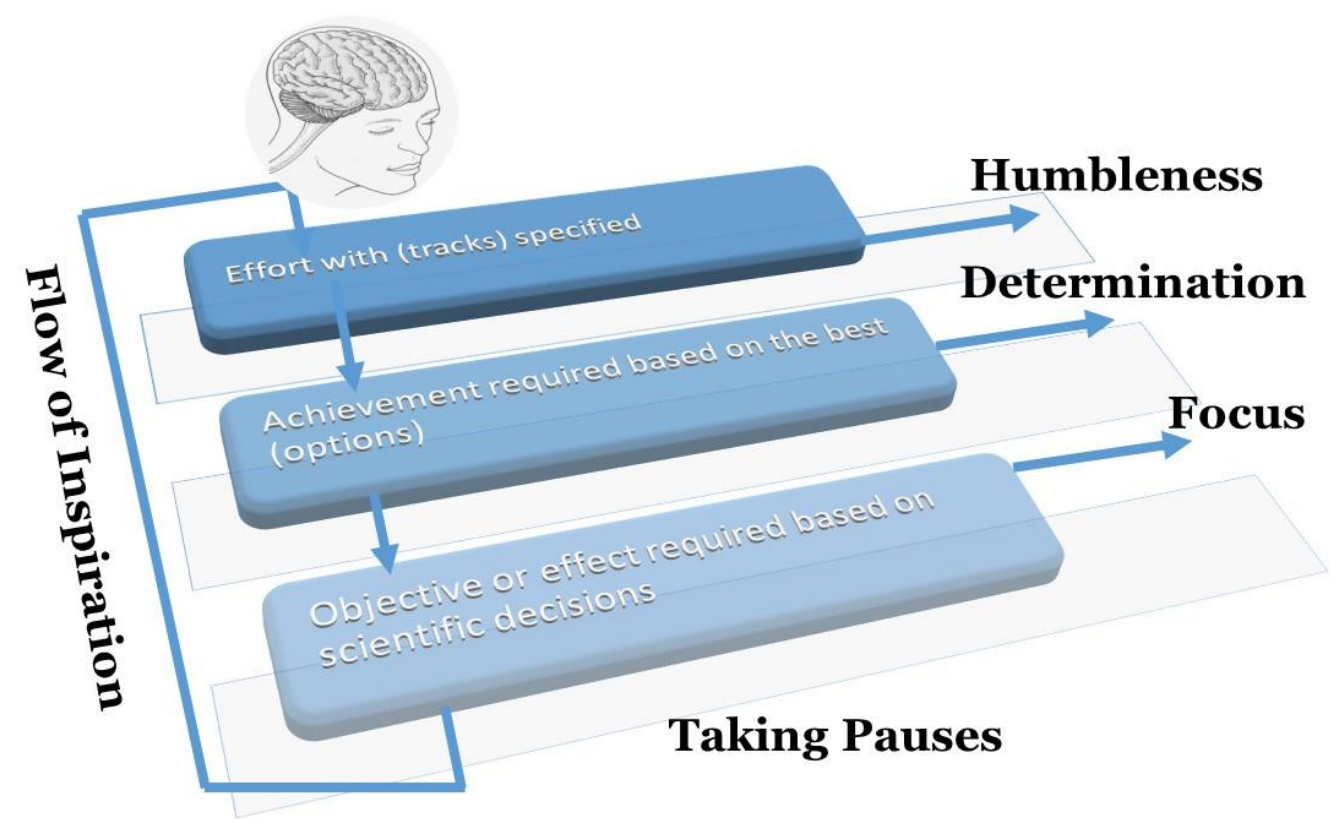

Figure 4. Youth Life-Purposefulness Framework

The framework helps to raise the ability to neutralise the effects on "youth life-purposefulness paths, choices and decisions making". A selection of critical primary and secondary dimensions that create an impact on the individual's life is expected - the framework target to acquire and then enhance life experiences. Figure (5) shows the main six steps of extracted from the program that can be part of any life-purposefulness journey. The journey starts with specifying the exploration frame for the life-purposefulness tracks. Then a visualisation of the real challenge would be explored to determine what assets are available to youth that would constitute the perception and to select the assumptions from which to start new paths. Based on these the earlier steps, new information would be built to help the participating youth to select the key options that would help them to start managing change and valuing the results. 


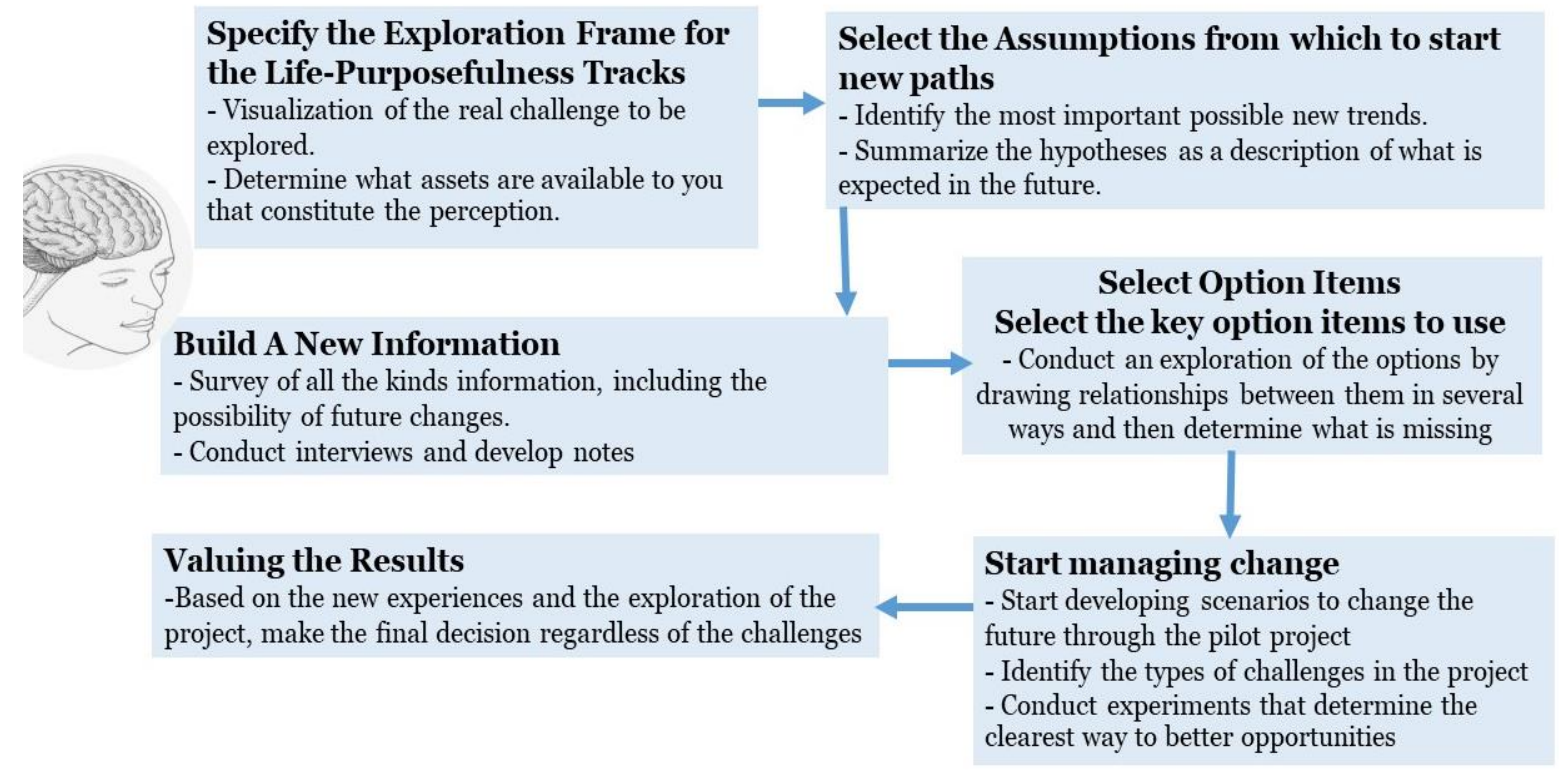

Figure 5. Illustrates the Journey of Life-Purposefulness until the Results Outcome

\subsection{Final Remarks}

Setting youth life-purposefulness program is highly essential for any country that is eager to build a competitive economy. Such a program can be more globally effective through precise approaches that would help to deliver youth with focused life goals and an inspiring spirit that ready to manage challenges without hesitation or procrastination. The success of such programs would establish a new wave of youth economy that can change the level of youth contribution to socio-economic issues and their level of contribution throughout their life span.

Despite the limitations of this study of both being carried only by researcher and his team in a specific setting and one country; the outcome of this paper can be generalised and recommended to be tested in different countries and with the youth of a variety of background. The life-purposefulness program and its framework carry lots of implications for both youth leaders and educators, besides they set a direction for national youth strategies. Further empirical research is suggested in the same line to cover the enormous gap in the literature in this area as it carries many perspectives for the future of youth and their expected role.

\section{References}

Amabile, T. M. (1982) Social psychology of creativity: A consensual assessment technique. Journal of Personality and Social Psychology, 43, 997-1013. https://doi.org/10.1037/0022-3514.43.5.997

Bandura, A. (1977) Self-efficacy: Toward a unifying theory of behavioral change. Psychological Review, 84, 191-215. https://doi.org/10.1037/0033-295X.84.2.191

Buheji, M. (2018a). Handbook of Youth Economy, AuthorHouse, UK. 
Buheji, M. (2018b). Re-Inventing Our Lives, A Handbook for Socio-Economic "Problem-Solving", AuthorHouse, UK.

Buheji, M. (2018c). Understanding the Power of Resilience Economy: An Inter-Disciplinary Perspective to Change the World Attitude to Socio-Economic Crisis, AuthorHouse, UK.

Buheji, M. (2019a). Designing a Curious Life, AuthorHouse, UK

Buheji, M. (2019b). Influence of visualised reflection on 'solving socio-economic problems' a case from youth economy forums, Int. J. Innovation and Learning, 25(1), 1-16. https://doi.org/10.1504/IJIL.2019.10016648

Cziksentmihalyi, M. (1990). Flow - The Psychology of optimal experience, Harper. https://www.researchgate.net/publication/224927532_Flow_The_Psychology_of_Optimal_E xperience, accessed on: 1/1/2019.

Dacey, J. (1989). Peak periods of creative growth across the lifespan. Journal of Creative Behaviour, 23(4). https://doi.org/10.1002/j.2162-6057.1989.tb00697.x

Deci, E., \& Ryan, R. (2000). The "what" and "why" of goal pursuits: Human needs and the self-determination of behavior. Psychological Inquiry, 11, 227-268.

Driouchi, A., \& Harkat, T. (2017). Counting the NEETs for Countries with no or less Data, Using Information on Unemployment of Youth Aged 15-24: The Case of Arab Countries. Online at https://mpra.ub.uni-muenchen.de/79330/ MPRA Paper No. 79330. https://www.researchgate.net/publication/317872278_Counting_the_NEETs_for_Countries_ with_no_or_less_Data_Using_Information_on_Unemployment_of_Youth_Aged_15-24_The _Case_of_Arab_Countries_Counting_the_NEETs_for_Countries_with_no_or_less_Data_Usi ng_Infor, accessed on: 1/1/2019.

Dweck, C. (1999). Self-theories: Their role in motivation, personality, and development. Philadelphia: Psychology Press.

Eisenhardt, K., \& Graebner, M. (2007) Theory building from cases: opportunities and challenges, Academy of Management Journal, 50(1), 25-32. https://doi.org/10.5465/amj.2007.24160888

Kashdan, T. (2009). Curious? Discover the missing ingredient to a fulfilling life. New York, NY: HarperCollins.

Kashdan, T., \& McKnight, P. (2009) Origins of purpose in life: Refining our understanding of a life well lived. Psihologijske Teme, 18(2), 303-316.

Kashdan, T., \& McKnight, P. (2013) Commitment to a Purpose in Life: An Antidote to the Suffering by Individuals with Social Anxiety Disorder, American Psychological Association, 13(6), 1150 -1159. https://doi.org/10.1037/a0033278

Kashdan, T., \& Steger, M. (2007). Curiosity and pathways to well-being and meaning in life: Traits, states, and everyday behaviors. Motivation and Emotion, 31, 159-173. https://doi.org/10.1007/s11031-007-9068-7 


\section{Macrothink}

International Journal of Human Resource Studies

ISSN 2162-3058 2019, Vol. 9, No. 4

Loewenstein, G. (1994). The psychology of curiosity: A review and reinterpretation. Psychological Bulletin, 116, 75-98. https://doi.org/10.1037/0033-2909.116.1.75

Sheldon, K., \& Kasser, T. (1998). Pursuing personal goals: Skills enable progress but not all progress is beneficial. Personality and Social Psychology Bulletin, 24, 1319-1331. https://doi.org/10.1177/01461672982412006

Silvia, P. (2001). Interest and interests: The psychology of constructive capriciousness. Review of General Psychology, 5, 270-290. https://doi.org/10.1037/1089-2680.5.3.270

Silvia, P. (2006). Exploring the psychology of interest. New York: Oxford University Press. https://doi.org/10.1093/acprof:oso/9780195158557.001.0001

Steger, M., \& Frazier, P (2005). Meaning in life: One link in the chain from religion to well-being. Journal of Counseling Psychology, 52, 574-582. https://doi.org/10.1037/0022-0167.52.4.574

Wong, P., \& Fry, P. (1998). The human quest for meaning: A handbook of psychological research and clinical application. Mahwah, NJ: Lawrence Erlbaum.

\section{Copyright Disclaimer}

Copyright for this article is retained by the author(s), with first publication rights granted to the journal.

This is an open-access article distributed under the terms and conditions of the Creative Commons Attribution license (http://creativecommons.org/licenses/by/4.0/). 